\title{
Duty Rosters and Workloads of Obstetricians in Germany: Results of a Germany-wide Survey
}

\section{Dienstmodelle und Arbeitsbelastung der geburtshilflich tätigen Ärzte in Deutschland: Ergebnisse einer deutschlandweiten Umfrage}

Authors

Johannes Neimann ${ }^{1 *}$, Julia Knabl2,3*, Julian Puppe ${ }^{4}$, Christian Michael Bayer ${ }^{5}$, Paul Gass ${ }^{5}$, Lena Gabriel ${ }^{6}$,

Birgit Seelbach-Goebel ${ }^{7}$, Johannes Lermann ${ }^{5}$, Sarah Schott ${ }^{8,9,10}$

Affiliations

1 Frauenklinik mit Brustzentrum, KRH Klinikum Siloah, Hannover, Germany

2 Klinikum der Universität München Klinik und Poliklinik für Frauenheilkunde und Geburtshilfe Campus Innenstadt, München, Germany

3 Department of Obstetrics, Klinik Hallerwiese, Nürnberg, Germany

4 Klinik und Poliklinik für Frauenheilkunde und Geburtshilfe, Uniklinik Köln, Köln, Germany

5 Frauenklinik, Universitätsklinikum Erlangen, Erlangen, Germany

6 Klinik für Frauenheilkunde, Geburtshilfe und Reproduktionsmedizin, Universitätsklinikum des Saarlandes, Homburg/Saar, Germany

7 Krankenhaus der Barmherzigen Brüder - Klinik St. Hedwig, Lehrstuhl für Frauenheilkunde und Geburtshilfe der Universität Regensburg, Regensburg, Germany

8 Universitätsfrauenklinik, Universitätsklinikum Heidelberg, Heidelberg, Germany

9 German Cancer Consortium (DKTK), Heidelberg, Germany

10 Deutsches Krebsforschungszentrum, Heidelberg, Germany

Key words

workload, specialization, obstetrics, work-life balance,

duty roster, perinatal center

Schlüsselwörter

Arbeitsbelastung, Weiterbildung, Geburtsmedizin,

Work Life Balance, Dienstmodelle, Perinatalzentrum

received 20.2.2017

revised 5.5.2017

accepted 9.5.2017

Bibliography

DOI https://doi.org/10.1055/s-0043-110863

Geburtsh Frauenheilk 2017; 77: 894-903 @ Georg Thieme

Verlag KG Stuttgart · New York | ISSN 0016-5751
Correspondence

Johannes Neimann

KRH Klinikum Siloah, Frauenklinik mit Brustzentrum

Stadionbrücke 4, 30459 Hannover, Germany

johannes.neimann@gmail.com

\section{ABSTRACT}

Background Compiling a daily hospital roster which complies with existing laws and tariff regulations and meets the requirements for ongoing professional training while also taking the legal regulations on the health of employees into account makes planning the duty roster a challenge. The aim of this study was to obtain a realistic picture of existing duty roster systems and of the current workloads of obstetricians in Germany.

Method This online survey was sent to 2770 physicians training to become obstetricians or specializing in specific areas of obstetric care. The survey consisted of an anonymized 95item questionnaire which collected data on different types of duty roster systems and the workload of obstetricians in Germany for the period from 17.02.2015 to 16.05.2015.

Results Out of a total of 2770 physicians who were contacted, 437 (16\%) completed the questionnaire. Across all forms of care, the care provided outside normal working hours usually (75\%) consisted of a combination of regular working times and on-call duty or even consisted entirely of standby duty. Level I perinatal centers were most likely $20 \%$ $(\mathrm{n}=88)$ to have a shift system in place. Working a shift system was significantly more common in care facilities which had previously carried out a job analysis. The number of physicians in hospitals who are present during the night shift was higher in facilities with higher numbers of births and in facilities which offered higher levels of care. In addition to regularly working overtime and the fact that often not all the hours worked were recorded, it was notable that the systems used to compile duty rosters often did not comply with legal regulations or with collectively agreed working hours nor were they compatible with the staff planning requirements. 
Outlook The results of this study show that the conditions of work, the working times, and the organization of working times in obstetric departments are in need of improvement. Recording the actual times worked together with an analysis of the activities performed during working times and while on standby would increase the level of transparency for employers and employees.

\section{ZUSAMMENFASSUNG}

Hintergrund Die Umsetzung einer gesetzes- und tarifkonformen Tagesplanung im Krankenhaus im Einklang mit einer kontinuierlichen Weiterbildung unter Berücksichtigung der vorgeschriebenen Regelungen zum Gesundheitsschutz von Arbeitnehmern stellt die Dienstplanung vor Herausforderungen. Ziel der vorliegenden Untersuchung ist es, ein realitätsnahes Bild der vorherrschenden Dienstmodelle und der derzeitigen Arbeitsbelastung von in der Geburtsmedizin tätigen Ärzten in Deutschland zu generieren.

Methode Diese Onlineerhebung wurde an 2770 Ärzte in Facharzt- und Schwerpunktweiterbildung versandt. Sie erfasst mit einem anonymisierten 95-Item-Fragebogen verschiedene Dienstmodelle und die Arbeitsbelastung von ge- burtshilflich tätigen Ärzten in Deutschland im Zeitraum vom 17.02.2015 bis 16.05.2015.

Ergebnisse Von 2770 ärztlichen Adressaten lagen 437 (16\%) Antwortbögen vor. Über alle Versorgungsformen hinweg wird der Dienst außerhalb der Regelarbeitszeit am häufigsten (75\%) in einer Kombination aus Regeldienst und Bereitschaftsdienst (BD) bzw. reinem BD organisiert. Ein Schichtsystem ist mit 20\% ( $n=88)$ am häufigsten in Perinatalzentren Level I etabliert. Es wird signifikant häufiger in Schichtdienst gearbeitet, wenn zuvor eine Arbeitszeitanalyse vorgenommen wurde. Die Anzahl der im Nachtdienst im Krankenhaus anwesenden Ärzte nimmt bei höherer Geburtenzahl sowie höherer Versorgungsstufe zu. Neben regelmäßigen Überstunden und oft inkompletter Arbeitszeiterfassung fällt insbesondere auf, dass die Dienstmodelle oft weder mit den gesetzlichen und tariflichen Regelungen noch mit den tatsächlichen Anforderungen an die Personalplanung vereinbar sind.

Ausblick Die vorliegenden Ergebnisse zeigen verbesserungsbedürftige Zustände in Bezug auf die Arbeits- und Dienstsituation sowie -organisation in geburtshilflichen Abteilungen. Insbesondere eine Erfassung der Arbeitszeit und Tätigkeitsanalysen im Dienst würden die Transparenz für Arbeitgeber und -nehmer erhöhen.

\section{Introduction}

Since 2005, all perinatal centers (PNCs) in Germany are classified into one of four levels of care, based on the complexity of the care provided at the center and on the regional provision of care and health services: level I perinatal centers I (PNC I), level II perinatal centers (PNC II), obstetric departments offering secondary care and short-term perinatal care (PC), and maternity hospitals which offer standard maternity care (MH). Level I and level II perinatal centers provide high-level tertiary or quaternary care for mother and child, with level I centers offering the most specialized treatment. This classification into four levels of care was done to ensure that comprehensive, high quality obstetric care is available across all of Germany [1]. The "Quality Assurance Agreement on the Care of Premature and Full-term Babies" on which this classification was based has been revised several times, most recently on 20.11.2014 [2]. The Agreement defines the criteria for medical care. A PNC I must ensure that at least one physician is always on duty in the obstetric department for all of the 24 hours and that a further physician is on call in the hospital. At least one of these physicians must be a specialist for "special obstetric care and perinatal medicine" or a physician with this specialization must be oncall by telephone. The Agreement did not give any further specifications on how work should be distributed or what form the duty rosters of obstetricians should take; full-time work and on-call duty are both possible. PNC I facilities are additionally expected to function as recognized training centers for the medical specialty "specialized obstetric care and perinatal medicine" to ensure that high-quality medical care will continue to be available in the future. According to the German Working Hours Act [3], the average hours of work per week must not exceed 48 hours and the maximum number of hours worked per week must not exceed 60 hours. For reasons of health protection, the hours spent on-call are classified as working time [4,5]. Employees are only allowed to opt out of this protection at their own request within the scope of so-called opt-out regulations which permit them to increase their average working hours up to a collectively agreed higher limit without compensatory time off.

The professional and legal requirements for obstetric care facilities and the laws on health and safety at work pose special challenges for the systems used to compile duty rosters. The increasing numbers of women working in the field of gynecology and obstetrics, where the percentage of female physicians is $64.8 \%$, rising to $82.3 \%$ in the age group up to 34 years $[6,7]$, and the family commitments of some mothers are some of the reasons why the percentage of physicians working part time is increasing. This creates an additional challenge when scheduling the roster [8].

The aim of this national survey of obstetricians working in Germany was to obtain a realistic picture of the models currently utilized in different hospitals to schedule the duty rosters. Secondary goals included collecting data on the current workloads in obstetrics in Germany relative to the level of care provided by the respective healthcare facility and identifying the resulting differences in the planning of shifts and duty rosters.

\section{Methods}

\section{Questionnaire}

The survey was conducted using an online questionnaire developed by the authors themselves which consisted of 95 items (Supplement 1), of which 93 were questions and two were comment 
fields. The first part (20 questions) collected basic data on demography and professional work and training. The second part collected data on part-time work [9], working hours, and the structure of working hours. A third part evaluated the participant's satisfaction. Survey questions considered to be essential for the study were marked as mandatory. The survey was compiled using www.surveymonkey.de and distributed along with its URL via the newsletter of the Young Forum of the German Society of Gynecology and Obstetrics (DGGG) to its 2770 members currently training to become specialists or doing additional advanced training. Information on how to participate in the survey was also published in the Thieme specialist journal "Geburtshilfe und Frauenheilkunde" and via the Thieme online network "Thieme Gyn-Community". Data were collected over a period of 3 months, from 17.02.2015 to 16.05.2015 with potential participants given the opportunity to participate in the survey during that period. Every study participant was required to actively give their consent to the evaluation of their data at the beginning of the study and to confirm that they were working in obstetrics at the time of the survey, otherwise they were excluded from the study.

\section{Statistical analysis}

Statistical analysis of the data was done using the open source software GNU PSPP version 0.8.5 and GraphPad Software Inc., San Diego US, Prism 5.0a. Unpaired samples and non-normally distributed samples were analyzed using the Mann-Whitney test and the t-test for paired samples. Categorical variables were analyzed using the $\mathrm{x}^{2}$-test.

\section{Results}

\section{Selection of datasets}

A total of 481 (17\%) out of the 2770 contacted persons participated in the study. Of these, 437 were working in obstetrics at the time of the survey and gave their consent to their data being analyzed. In the subsequent analysis, these 437 respondents were taken as the total population with the figure of 437 set at $100 \%$. Responses to all survey questions are set against this figure, and the number or percentage of participants who declined to answer a specific question is reported (n. s. = not specified).

\section{Characteristics of participants}

The majority of participants were German $(89 \%, n=392$, n. s. $=61)$ and female $(77 \%, n=326$, n. s. $=59)$. At the time of the survey all of them were in training to become specialists in gynecology and obstetrics $(52 \%, n=230, n .5 .=78)$. Detailed characteristics of the participants are given in $>$ Table 1 . The majority of participants worked full time (FT $64 \%, n=297$, n. s. $=80$ ). Detailed data on part-time working schedules (PT) were part of a subgroup analysis and have already been published elsewhere [9]. The distribution of respondents according to the level of perinatal care offered by their facility is shown in $\boldsymbol{\nabla}$ Fig. $\mathbf{1}$.

\section{Types of duty rosters}

In obstetrics, all conceivable combination of full-time work with and without shift work (SW), internal on-call duty (IOC) and external on-call duty (EOC) were reported across all levels of care, from general maternity hospitals to facilities offering tertiary and qua-

- Table 1 Characteristics of participants.

\begin{tabular}{|c|c|c|c|c|c|c|}
\hline & \multicolumn{2}{|c|}{ Total } & \multicolumn{2}{|c|}{ Women } & \multicolumn{2}{|c|}{ Men } \\
\hline \multicolumn{7}{|c|}{437 physicians working in obstetric departments who consented to data analysis } \\
\hline Gender & $\mathrm{n}=$ & 437 & & & & \\
\hline - women & 326 & $74.60 \%$ & & & & \\
\hline - men & 96 & $21.97 \%$ & & & & \\
\hline - not specified (n.s.) & 15 & $3.43 \%$ & & & & \\
\hline Age & $\mathrm{n}=$ & 437 & $\mathrm{n}=$ & 326 & $\mathrm{n}=$ & 96 \\
\hline . $<30$ years & 83 & $18.99 \%$ & 73 & $22.39 \%$ & 10 & $10.42 \%$ \\
\hline - 30-35 years & 201 & $46.00 \%$ & 155 & $47.55 \%$ & 46 & $47.92 \%$ \\
\hline - 36-40 years & 66 & $15.10 \%$ & 54 & $16.56 \%$ & 12 & $12.50 \%$ \\
\hline - 41-50 years & 44 & $10.07 \%$ & 32 & $9.82 \%$ & 12 & $12.50 \%$ \\
\hline - 51-60 years & 20 & $4.58 \%$ & 11 & $3.37 \%$ & 9 & $9.38 \%$ \\
\hline - 61 years and older & 8 & $1.83 \%$ & 1 & $0.31 \%$ & 7 & $7.29 \%$ \\
\hline - n.s. & 15 & $3.43 \%$ & & & & \\
\hline Nationality ( $n=438 ; 1 \times$ dual nationality, therefore $101 \%$ ) & $\mathrm{n}=$ & 437 & $n=$ & 326 & $\mathrm{n}=$ & 96 \\
\hline - German & 392 & $89.70 \%$ & 307 & $94.17 \%$ & 85 & $88.54 \%$ \\
\hline - other & 29 & $6.64 \%$ & 19 & $5.83 \%$ & 11 & $11.46 \%$ \\
\hline - n.s. & 16 & $3.66 \%$ & & & & \\
\hline
\end{tabular}


- Table 1 Characteristics of participants. (Continued)

\begin{tabular}{|c|c|c|c|c|c|c|}
\hline \multirow[b]{2}{*}{$\begin{array}{l}\text { How many children below the age of } 17 \text { years live in your } \\
\text { household? }\end{array}$} & \multicolumn{2}{|c|}{ Total } & \multicolumn{2}{|c|}{ Women } & \multicolumn{2}{|c|}{ Men } \\
\hline & $\mathrm{n}=$ & 437 & $\mathrm{n}=$ & 326 & $\mathrm{n}=$ & 96 \\
\hline - none & 250 & $57.21 \%$ & 190 & $58.28 \%$ & 60 & $62.50 \%$ \\
\hline - 1 & 74 & $16.93 \%$ & 55 & $16.87 \%$ & 19 & $19.79 \%$ \\
\hline .2 & 74 & $16.93 \%$ & 61 & $18.71 \%$ & 13 & $13.54 \%$ \\
\hline .3 & 19 & $4.35 \%$ & 16 & $4.91 \%$ & 3 & $3.13 \%$ \\
\hline . 4 & 3 & $0.69 \%$ & 2 & $0.61 \%$ & 1 & $1.04 \%$ \\
\hline .5 & 2 & $0.46 \%$ & 2 & $0.61 \%$ & 0 & $0.00 \%$ \\
\hline - n.s. & 15 & $3.43 \%$ & & & & \\
\hline Extent of employment & $\mathrm{n}=$ & 437 & $\mathrm{n}=$ & 312 & $\mathrm{n}=$ & 89 \\
\hline - part time & 104 & $23.80 \%$ & 100 & $32.05 \%$ & 4 & $4.49 \%$ \\
\hline - full time & 297 & $67.96 \%$ & 212 & $67.95 \%$ & 85 & $95.51 \%$ \\
\hline " n.s. & 36 & $8.24 \%$ & & & & \\
\hline Professional position & $n=$ & 437 & $\mathrm{n}=$ & 313 & $n=$ & 90 \\
\hline - intern/resident physician & 230 & $52.63 \%$ & 199 & $63.58 \%$ & 31 & $34.44 \%$ \\
\hline - specialist (gynecology and obstetrics) & 81 & $18.54 \%$ & 63 & $20.13 \%$ & 18 & $20.00 \%$ \\
\hline - specialist (other medical specialty) & 3 & $0.69 \%$ & 1 & $0.32 \%$ & 2 & $2.22 \%$ \\
\hline - senior physician & 57 & $13.04 \%$ & 34 & $10.86 \%$ & 23 & $25.56 \%$ \\
\hline - consultant/deputy principal consultant & 12 & $2.75 \%$ & 7 & $2.24 \%$ & 5 & $5.56 \%$ \\
\hline - principal consultant & 17 & $3.89 \%$ & 7 & $2.24 \%$ & 10 & $11.11 \%$ \\
\hline - other & 3 & $0.69 \%$ & 2 & $0.64 \%$ & 1 & $1.11 \%$ \\
\hline " n.s. & 34 & $7.78 \%$ & & & & \\
\hline $\begin{array}{l}\text { Interns/residents }(n=230) \text { : which year of training as a specialist } \\
\text { are you currently in? }\end{array}$ & $\mathrm{n}=$ & 230 & $\mathrm{n}=$ & 199 & $\mathrm{n}=$ & 31 \\
\hline \multicolumn{7}{|l|}{ Year of training to become a specialist: } \\
\hline - 1st year & 20 & $8.70 \%$ & 18 & $9.05 \%$ & 2 & $6.45 \%$ \\
\hline - 2nd year & 38 & $16.52 \%$ & 29 & $14.57 \%$ & 9 & $29.03 \%$ \\
\hline - 3rd year & 40 & $17.39 \%$ & 37 & $18.59 \%$ & 3 & $9.68 \%$ \\
\hline - 4th year & 62 & $26.96 \%$ & 51 & $25.63 \%$ & 11 & $35.48 \%$ \\
\hline - 5th year & 56 & $24.35 \%$ & 50 & $25.13 \%$ & 6 & $19.35 \%$ \\
\hline - 5th year and simultaneously 1 st year of further specialization & 6 & $2.61 \%$ & 6 & $3.02 \%$ & 0 & $0.00 \%$ \\
\hline - Concluded specialist training, not passed exam yet & 8 & $3.48 \%$ & 8 & $4.02 \%$ & 0 & $0.00 \%$ \\
\hline " n.s. & 0 & $0.00 \%$ & & & & \\
\hline Level of care provided by the facility & $\mathrm{n}=$ & 437 & $\mathrm{n}=$ & 302 & $\mathrm{n}=$ & 83 \\
\hline - primary care/general maternity hospital & 82 & $18.76 \%$ & 69 & $22.85 \%$ & 13 & $15.66 \%$ \\
\hline - secondary care and short-term perinatal care & 22 & $5.03 \%$ & 17 & $5.63 \%$ & 5 & $6.02 \%$ \\
\hline - level II perinatal center (tertiary care) & 54 & $12.36 \%$ & 45 & $14.90 \%$ & 9 & $10.84 \%$ \\
\hline - level I perinatal center (specialized tertiary/quaternary care) & 225 & $51.49 \%$ & 170 & $56.29 \%$ & 55 & $66.27 \%$ \\
\hline " unknown & 1 & $0.23 \%$ & 0 & $0.00 \%$ & 1 & $1.20 \%$ \\
\hline " other & 1 & $0.23 \%$ & 1 & $0.33 \%$ & 0 & $0.00 \%$ \\
\hline - n.s. & 52 & $11.90 \%$ & & & & \\
\hline
\end{tabular}

ternary care. $\mathbf{F i g .} \mathbf{2}$ shows the organization of duty rosters in the different hospital types. Twenty-one participants (5\%) reported that night duty was not scheduled as shift work or internal on-call duty. Across all levels of care, in-hospital work outside of normal working hours was usually organized either as purely on-call duty or as a combination of regular working hours and on-call duty. In this survey, on-call duty was the most common form of roster used to cover night shifts during the week and to cover all weekend shifts (day and night shifts). A total of $75 \%(n=329$, n. s. $=56)$ of respondents reported that their duty roster included standby 


\section{Distribution of respondents according to the level of care provided in the facility}

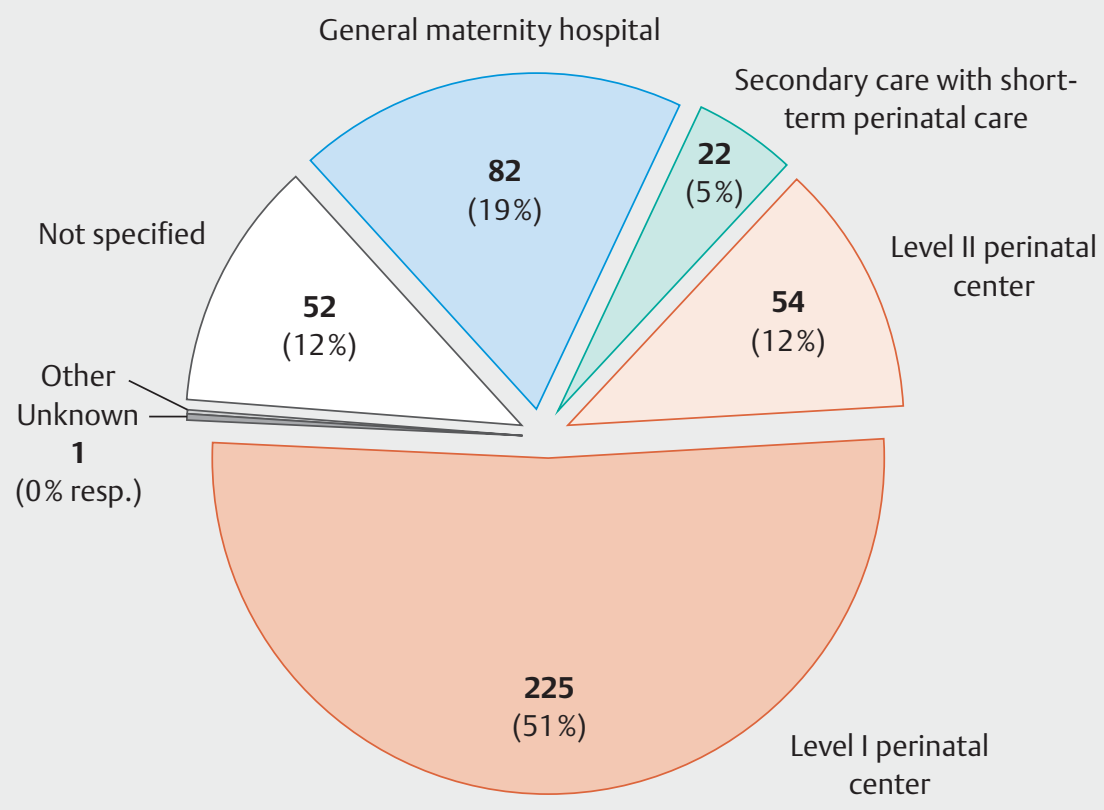

Fig. 1 Distribution of respondents according to the level of care provided by the hospital.

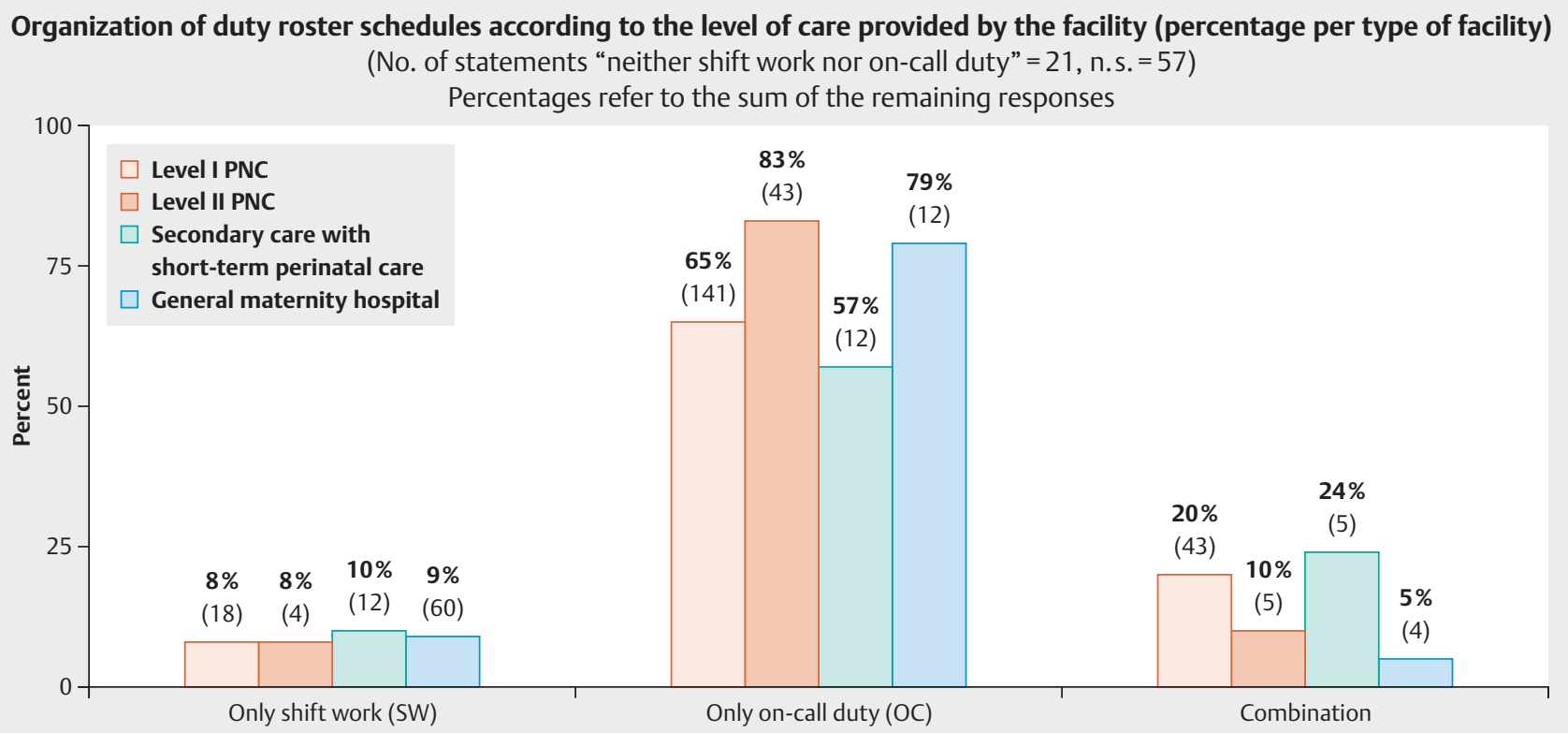

- Fig. 2 Organization of duty rosters according to the level of care provided in the facility (percentage per type of facility). 359 participants provided usable data $=100 \%$. The statement "neither SW (shift work) nor OC (on-call duty)" is not shown, $\mathrm{n}=21$. Not specified (n. s.) $=57$.

duty to cover the night shift. At the same time, 63\% ( $n=277$, n. s. $=113$ ) reported that all on-call duty rosters included night shifts from 9 p.m. to 6 a.m.

Shift work was much rarer: a shift work roster (only shift work or a combination of on-call duty and shift work) was only used in
$20 \%(n=88$, n. s. $=71)$ of cases. There was no clear correlation between the extent of shift work scheduled and the level of care provided by the hospital facility. However, combinations of both systems increased as the numbers of physicians present in hospital increased. Similarly, a high number of births was found to be cor- 


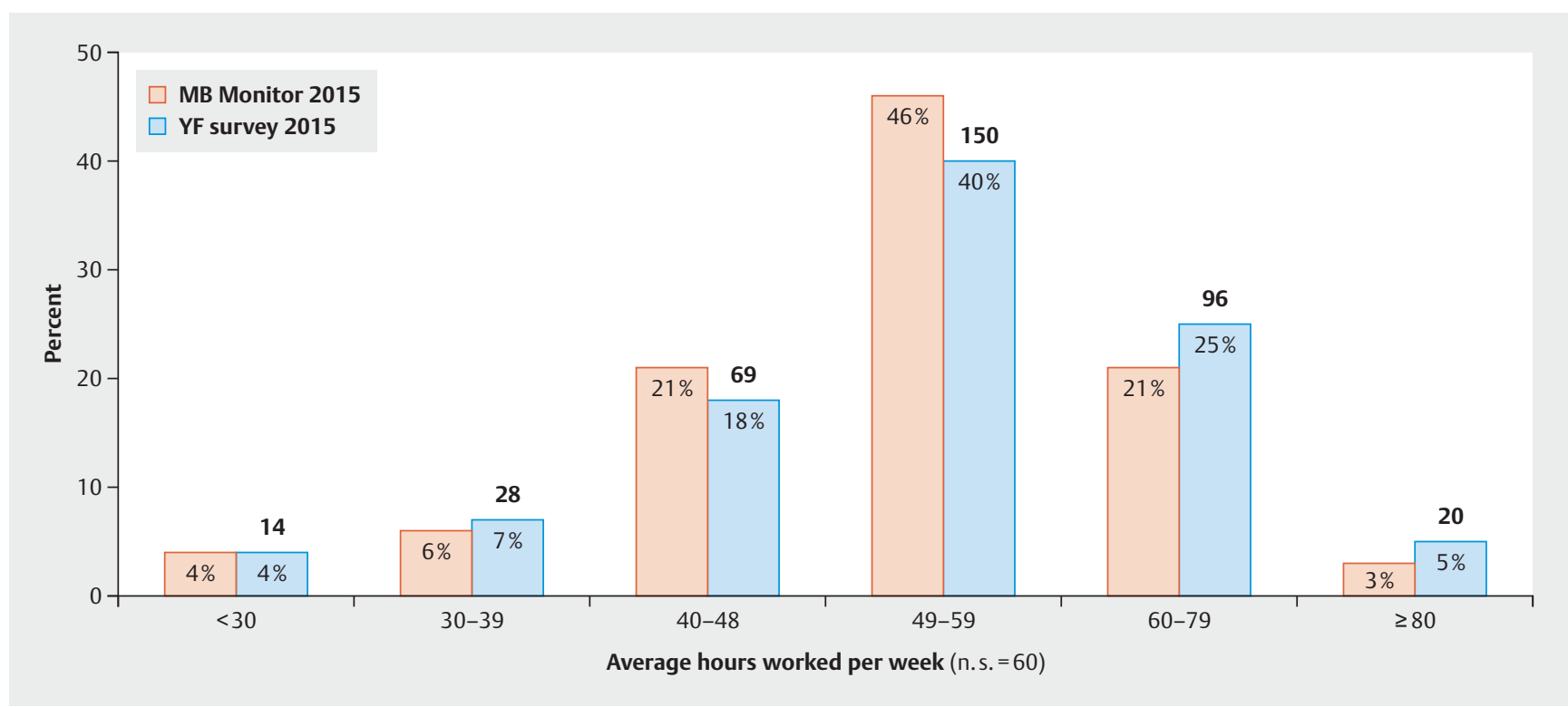

- Fig. 3 Average weekly working hours. Comparison of the survey by Young Forum (YF) (377 participants answered the question $=100 \%$, not specified [n. s.] = 60) with the data from the Marburger Bund (MB) Monitor 2015.

related with shift work: participants $(n=366$, n. s. $=71)$ reported that on average $20 \%$ of scheduled work was shift work across all groups. If the facility provided care for $>1500$ births annually $(n=207), 29 \%$ reported working in shifts; in those facilities which provided care for $>2000$ births $(n=114)$ annually, $43 \%$ worked in shifts. Participants also reported that shift work was significantly more common in facilities which had previously carried out a job analysis $(p<0.01)$.

External standby duty was part of the duty roster of $30 \%$ $(n=132)$ of participants $(n=362$, n.s. $=75)$. In this group $(n=132)$, external on-call duty was often used as a way of organizing so-called back-up on-call duty $(n=168)$ and less often when organizing (additional) standard on-call duty $(n=71)$.

Participants reported differences between the duty rosters on weekends and those for the regular working week (defined here as Monday to Friday): shift lengths on the weekend were significantly longer than in the week. This difference was less pronounced in departments which had only shift work $(n=31)$ compared to departments with only on-call duty or a combination of shift work and on-call duty $(\mathrm{n}=324)$.

In departments where duty rosters were scheduled only as shifts, weekends were almost exclusively covered by 2 12-hour shifts $(n=27)$. This was also the most common schedule $(n=22)$ during the regular week as well. Because of the limited numbers, further statistically reliable differentiations were not possible.

In departments which used on-call rosters $(n=324)$ there was a difference between weekend and workday shifts: on-call shifts of 20 to 24 hours were the most common $(n=162)$, followed by 12-14 hour on-call shifts $(n=62)$ or shifts of other duration $(n<7$, respectively). Shifts during the week tended to be shorter ( $n=99$ for 20-24 hour shifts).

329 of all participants reported that their duty roster included standby duty on a pro rata basis. In 192 cases the duty roster man- dated the highest possible level of on-call duty permitted by the respective labor agreements. 104 of the participants (24\%) reported that they worked up to four on-call duty shifts, 203 participants (46\%) worked between five and nine, and 5 respondents worked ten or more on-call shifts every month. More than half of the participants (55\%) reported that on average, it was not possible to do only the amount of work expected for their on-call duty roster: the deviation from the envisaged amount of work was most striking in level I perinatal centers and differed significantly from departments offering standard maternity care $(p=0.01)$ and those offering advanced secondary and short-term perinatal care $(p=0.03) .90 \%(n=290)$ of all respondents $(n=324$, n. s. $=113)$ reported that tasks which were supposed to be carried out during normal working hours (normal working time tasks) were regularly carried out whilst on call.

\section{Working hours}

- Fig. 3 shows the real number of hours worked per week (the sum of all hours worked full time including overtime and internal on-call duty but excluding external on-call duty) compared to the data of the Marburger Bund (MB) Monitor 2015, the publication of the professional medical association and trade union for physicians in Germany [10]. $43 \%$ of respondents $(n=189)$ had agreed to an opt-out arrangement, $34 \%(n=150)$ had rejected such an arrangement, $11 \%(n=48)$ were not sure whether or not they had agreed to such an arrangement (n. s. $=49 ; 11 \%$ ).

Just under half of the participants $(48 \%, n=207$, n. s. $=76)$ reported that their employer systematically recorded their working hours, either by documenting the hours manually (online) or by using an electronic timekeeping system. $11 \%(n=49)$ of participants reported that they were not able to record all of the hours they effectively worked, although the majority $(53 \%, n=230)$ did not supply any information on this point. In the free-text answers 
( $n=22$ ), participants stated that the hours they worked over and above their regular planned working times could not be entered into the registration system or that the system automatically logged them out once they had worked the permitted maximum number of working hours. The majority of respondents $(71 \%$, $n=311$, n. s. $=121$ ) reported that they regularly worked overtime, irrespective of the type of care provided by their department; in $24 \%$ of cases $(n=104$, n. s. $=77$ ) they were ordered to do overtime. In departments which handled up to 1000 births annually, physicians worked significantly less overtime than in centers which handled $>1000$ births (74\% vs. $89 \%, p<0.01$ ). There was no significant difference between the groups "1001-2000 birth" and "> 2000 births". Likewise, there were no significant differences between groups with regard to the type of employer, the level of care provided by the facility, whether or not the work was shift work, the amount of in-hospital on-call duty, whether working times were recorded prior to deciding on the type of duty rosters, or the number of children up to the age of 17 living in their household. The survey did not explicitly ask about the reasons for overtime. Common reasons listed in the free-text answers mentioned unfilled positions and staff shortages.

\section{Personnel planning for the respective care levels}

The overwhelming majority of participants reported that at least one physician was present in the department outside normal working hours; there was only one case where the duty physician was only on external on-call duty. The number of physicians present in hospital varied greatly, depending on the number of births handled by the facility and the type of care provided ( $\vee$ Fig. 4). The higher number of physicians present in secondary and tertiary care facilities and in PNCs compared to the number in general hospitals was statistically significant $(p \leq 0.0001)$. A sub-analysis of PNCs according to the level of care offered by the respective facility showed a significantly higher number of on-duty physicians in level I PNCs compared to facilities offering shortterm perinatal care and level II PNCs $(p=0.0002$ and $p=0.0001)$. We found no significant differences between facilities offering short-term perinatal care and level II PNCs $(p=0.42) .31 \%$ of all participants $(n=137)$ reported that no specialist physician was on duty in the hospital during the night shift. Of the 44 participants who had less than one year's experience in obstetrics, ten were on duty at night with no specialist physician present; six of them were working in level I PNCs. 269 participants (62\%) felt that the distribution of working hours in their hospital negatively affected their health.

\section{Discussion}

This survey aimed to investigate working times and workloads in obstetric departments across Germany. The data showed that differences in duty rosters were largely determined by the number of births handled by the facility and the level of perinatal care it provided. Duty rosters on weekdays differed from those of weekends, with the most common working times consisting of combinations of on-call/standby duty. The most important predictors for shift work were a high number of births in the facility and a prior job analysis with recording of working times. A number of free-text comments worried about potential financial losses following the introduction of shift work, which could lead to a reluctance to implement shift work. Combinations of both systems tended to increase with higher numbers of physicians on standby in hospital. The free-text comments suggest that the real staffing needs could be met better by using different types of duty systems.

The overwhelming use of systems with only a few shifts on weekends (2-shift system, long on-call hours) raises the question whether the duty system used on weekends is driven more by the wish to reduce the number of hours on duty on weekends rather than by the actual staffing requirements. This was suggested by the free-text comments. In contrast, weekday working hours appeared to correspond more closely to the real staffing needs.

The majority of respondents reported that the amount of work they performed while on standby exceeded the amount prescribed for their level of on-call duty. This is illegal for the highest level of standby duty, because, according to the definition, the percentage of time during which no work is performed must be greater than the hours worked while on standby, otherwise regularly scheduling standby duty is not permissible. In practice, there appears to be some difficulty in differentiating between permissible demands to perform work while on standby (up to an average of $50 \%$ of the time) and the system of remuneration (assessment as working time with up to $100 \%$ per hour). Even departments with only one physician on duty in hospital on weekends stated that sometimes the scheduled work roster consisted only of standby duty. Such reports need to be evaluated critically as they point to a potential misunderstanding. In addition to standard tasks such as planned visits to specific patients or being summoned to perform check-ups or operations, enough time must be left for unplanned tasks to ensure that the average time actually worked while on standby duty is $<50 \%$ [11]. As can be inferred from the free-text comments, such work is nevertheless regularly carried out. The introduction of a shift system or a combination of full time work/regular working hours and standby duty would be best practice.

The average hours worked per week determined in our study largely correspond to the data collected by the Marburger Bund in the same year, although with a tendency to be even higher than reported by the Marburger Bund [10]. The differences may be due to the fact that in our study a higher percentage of respondents worked in university hospitals $(30 \%[n=133$, n. s. $=96]$ vs. $18 \%$ Marburger Bund [MB] Monitor 2015) and the number of interns/ residents was also higher in our study (53\% of responses vs. $40 \%$ MB Monitor 2015). The high number of overtime hours worked by the respondents suggests that personnel planning in obstetric departments may not be in line with demand.

The surprising finding was that notwithstanding the increasing use of electronic timekeeping systems and collective agreements and despite significant penalties for non-compliance with the Working Hours Act (ArbZG), only $47 \%(n=207$, n. s. $=121$ ) of employers in obstetric medicine appeared to systematically record all of the time worked (compared to the figure of $73 \%$ reported in MB Monitor). Proper recording would allow changes in staffing requirements to be identified early and adjustments to be made. This is suggested by the findings of this study: facilities which 


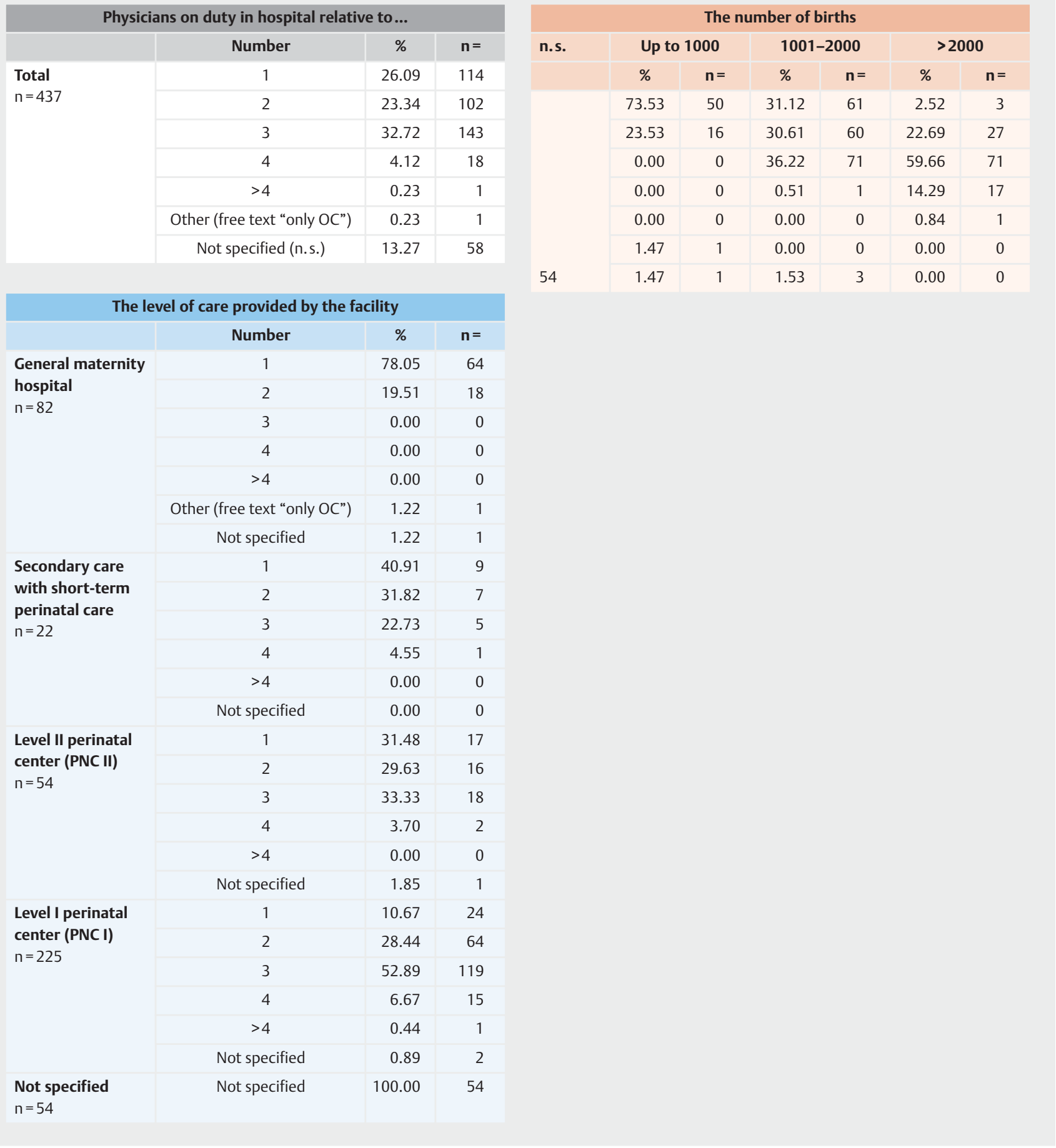

- Fig. 4 Physicians on duty in hospital relative to the number of births and the level of care provided by the facility.

had previously undertaken a job analysis were significantly more likely to have shift work systems in place.

In addition to the above-mentioned labor law considerations, this survey has also revealed safety-related problems: obstetric work requires a maximum of concentration, as the right lifechanging decisions have to be made within the space of just a few minutes to ensure the safety of mother and child. Long aver- age working hours, frequent overtime and inadequate choice of duty roster systems can have far-reaching consequences. It is well known that increased workloads lead to higher transmission rates of multi-resistant pathogens [12] and longer working times lead to an increase in the frequency of accidents und the probability of mistakes [13]. Recent occupational research has modelled patient risk with regard to medical malpractice and accidents as a 
function of the duty roster system and shift system used in medical centers and suggested that safety needs to be optimized across all levels of medical training [14]. Moreover, high workloads at night increase the individual's health risk over the longer term [15]. This survey showed a high subjective perception that work schedules had an adverse effect on health. The findings are comparable with the data of MB Monitor 2015 (61\% [ $n=269$, n. s. $=132$ ] vs. $72 \%)$.

Treatment in hospital must at all times comply with the standards expected of medical specialists. According to the quality standards proposed by the Federal Joint Commission (Gemeinsamer Bundesausschuss, G-BA), specialized obstetric care must be available in PNCs. According to the data in our survey no specialist physician was on site in $17 \%(n=37)$ of level I PNCs.

However, it should be noted that, given the current relative shortage of doctors, it is important to ensure that training for obstetricians and further training in "specialized obstetric care and perinatal medicine" is available to provide comprehensive specialist obstetric care in the future as well.

\section{Strengths and limitations of this survey}

This survey is the first national assessment of duty roster systems and workloads in obstetrics in the Federal Republic of Germany. Physicians at all levels working in obstetric departments participated in the study. This survey was primarily aimed at physicians training to become specialists or in advanced training. Other subgroups were also included, but these subgroups (e.g. chief physicians) were very small. This means that great caution should be used before using individual findings as a basis for further deliberations. Nevertheless, the distribution was sufficiently homogeneous across all types of in-hospital care and across all levels of medical training. With 437 respondents, the number of participants in our study corresponds to the usual group size of cohorts reported in articles on workloads used for comparative analysis [16-19]. The small sample sizes mean that bias is possible. The data presented here on duty roster systems and workloads are in accordance with the expected findings anticipated by the study group of the Young Forum when they designed the study and also reflect the authors' daily experience. The authors considered that the number of respondents who worked in level I PNCs was disproportionately high. One reason for this could be the composition of the Young Forum study group; a further reason could be the membership structure of the DGGG as a scientific society which attracts more research-oriented physicians. This could have resulted in a negative selection. A personalized survey code was not sent out. In theory, repeat participation can therefore not be excluded. However, a manual review of the datasets found no double entries (>90\% agreement).

In the opinion of the authors, the statements made by a few respondents that their duty roster schedule comprised neither shift work nor standby duty $(n=21)$ are not plausible. Differentiating between shift work and standby duty is done based on collective bargaining agreements which can vary greatly. After considering the free-text comments, the authors therefore assume that - despite the explanatory notes next to the respective questions - for some of the participants the differences in work roster systems was not clear enough for them to give correct answers.
This could have led to a slight underrepresentation of shift-work models. But if the respondents who did not provide data on the work roster system used in their facility were included in the group doing shift work, there would still be no significant change in the respective distributions shown.

The same applies to the term "medical specialist". On the one hand this was understood to refer to the status of the physician as a medical specialist; it was also understood to refer to the organizational structure of the department. This could lead to differences in the understanding of the term "intern/resident physician". To avoid misunderstandings and ambiguities, future studies should clearly differentiate between the status of medical specialist and working in the capacity of an intern/resident physician with/without specialist training.

As it was an anonymized survey, no data on the location and the number of physicians working in the respective healthcare facility was included. Using the questionnaire it was not possible to infer what work the individual performed based on the type of duty roster. It was not possible to determine whether the obstetric work performed should be classified as standby duty or shift work. This would require a survey which differentiated according to the type of work performed. The long list of questions covering several topics and the expected time to complete the survey of around 15 minutes may have deterred prospective participants from taking part in the survey.

\section{Outlook}

The results of our survey point to some clear deficiencies in the structure and organization of obstetric departments which may have potentially serious consequences for the quality of care. Given the current trend of centralization and the increased closures of obstetric departments because of unfavorable expenditure/ revenue ratios as well as the known fluctuations in patient flows in obstetrics, staffing needs should be regularly determined based on the actual amount of work carried out (recording of tasks). After taking legal, medical and structural conditions into account, identifying some (problematic) key areas could help to adapt the duty roster systems used in obstetric departments so as to improve the health of the physicians working there and reduce the liability risk for the persons responsible for the duty roster. The management usually delegates the responsibility for scheduling duty rosters to the departmental heads. The medical directors or departmental heads who ultimately approve the duty roster and tolerate departures from the planned schedule (e.g. overtime) are personally liable for violations of the German Occupational Safety and Health Act (ArbSchG) and the Working Hours Act.

As the demands made of obstetric departments vary greatly according to regional, structural and traditional differences, there can be no single, universally transferable solution for obstetric working hours. We were not able to deduce the ideal duty roster model for obstetrics from our data. There are different equally valid answers to organizational questions which comply with the law and with collective bargaining agreements. For example, the need for $100 \%$ coverage by a doctor could be met by either one doctor working a shift or two doctors on standby.

It would also be sensible to include foreseeable influencing variables such as illness and absences due to pregnancy/parental 
leave in the planning process. Planning would need to start by reviewing the requirements for medical staff (determination of the range of services offered) and the requirements laid down in current labor legislation (permissible duty roster models) and reconciling them with the current conditions in the facility (job analysis). This could be a way forward which, over the longer term, would improve the safety of the care environment where we treat the patients and children entrusted to our care.

\section{Acknowledgement}

We would like to thank the people who participated in the survey, the Central Office of the DGGG and in particular the study group of the Young Forum of the DGGG for their support.

\section{Conflict of Interest}

The authors declare that they have no conflict of interest.

\section{References}

[1] IQTIG - Institut für Qualitätssicherung und Transparenz im Gesundheitswesen. Welche Arten von Krankenhäusern für eine Geburt gibt es? Online: https://www.perinatalzentren.org/; last access: 16.11.2015

[2] Gemeinsamer Bundesausschuss. Qualitätssicherungs-Richtlinie Früh- und Reifegeborene - QFR-RL. Online: https://www.g-ba.de/informationen/ richtlinien/41/; last access: 16.11.2015

[3] §3 ArbZG GEREv

[4] SIMAP RC-J, Rechtssache C-151/02

[5] Bernd G. Arbeitsrecht: Bereitschaftsdienst ist Arbeitszeit. Dtsch Arztebl 2013; 39: 2

[6] Osterloh F. Ärztestatistik: Mehr Ärztinnen, mehr Angestellte. Dtsch Arztebl 2014; 111: A672, B-580, C-560
[7] Osterloh F. Ärztestatistik: Ärztemangel bleibt bestehen. Dtsch Arztebl 2015; 112: A-703, B-597, C-577

[8] Gibis B, Heinz A, Jacob RD et al. The career expectations of medical students: findings of a nationwide survey in Germany. Dtsch Arztebl Int 2012; 109: 327-332

[9] Schott S, Lermann J, Eismann S et al. Part-time employment of gynecologists and obstetricians: a sub-group analysis of a Germany-wide survey of residents. Arch Gynecol Obstet 2016; DOI: 10.1007/s00404-0164220-9

[10] MarburgerBund. MB-Monitor 2015. 2015. Online: https://www. marburger-bund.de/sites/default/files/dateien/seiten/mb-monitor-2015/ gesamtauswertung-mb-monitor-2015-pk.pdf; last access: 11.11.2016

[11] §10 Abs, 1 S. 2 TV-Ärzte VKA (Legaldefinition des Bereitschaftsdienstes)

[12] Vicca AF. Nursing staff workload as a determinant of methicillin-resistant Staphylococcus aureus spread in an adult intensive therapy unit. J Hosp Infect 1999; 43: 109-113

[13] Rogers AE, Hwang WT, Scott LD et al. The working hours of hospital staff nurses and patient safety. Health Aff (Millwood) 2004; 23: 202-212

[14] Pearlman MD. Patient safety in obstetrics and gynecology: an agenda for the future. Obstet Gynecol 2006; 108: 1266-1271

[15] Vetter C, Devore EE, Wegrzyn LR et al. Association between rotating night shift work and risk of coronary heart disease among women. JAMA 2016; 315: 1726-1734

[16] Puppe J, Dieterich M, Bayer C et al. Senology in gynaecology specialist training: a baseline survey from 2014. Geburtsh Frauenheilk 2016; 76: 564-569

[17] Hancke K, Igl W, Toth B et al. Work-life balance of German gynecologists: a web-based survey on satisfaction with work and private life. Arch Gynecol Obstet 2014; 289: 123-129

[18] Reif P, Schott S, Boyon C et al. Does knowledge of fetal outcome influence the interpretation of intrapartum cardiotocography and subsequent clinical management? A multicentre European study. BJOG 2016; DOI: 10.1111/1471-0528.13882

[19] Knieper C, Ramsauer B, Hancke K et al. "Pregnant and Operating”: evaluation of a Germany-wide survey among female gynaecologists and surgeons. Geburtsh Frauenheilk 2014; 74: 875-880 